\title{
Glutamate Mechanisms Underlying Opiate Memories
}

\author{
Jamie Peters ${ }^{1}$ and Taco J. De Vries ${ }^{1,2}$ \\ ${ }^{1}$ Department of Anatomy and Neurosciences, Neuroscience Campus Amsterdam, VU University Medical \\ Center, 1081BT Amsterdam, The Netherlands \\ ${ }^{2}$ Department of Molecular and Cellular Neurobiology, Center for Neurogenomics and Cognitive Research, \\ Faculty of Earth and Life Sciences, VU University, 1081HVAmsterdam, The Netherlands \\ Correspondence: tj.devries@vumc.nl
}

\begin{abstract}
As the major excitatory neurotransmitter in the brain, glutamate plays an undisputable integral role in opiate addiction. This relates, in part, to the fact that addiction is a disorder of learning and memory, and glutamate is required for most types of memory formation. As opiate addiction develops, the addict becomes conditioned to engage in addictive behaviors, and these behaviors can be triggered by opiate-associated cues during abstinence, resulting in relapse. Some medications for opiate addiction exert their therapeutic effects at glutamate receptors, especially the NMDA receptor. Understanding the neural circuits controlling opiate addiction, and the locus of glutamate's actions within these circuits, will help guide the development of targeted pharmacotherapeutics for relapse.
\end{abstract}

\begin{abstract}
$A$ ddiction to opiate drugs, like heroin and Amorphine, is a complex disease that begins with opiate exposure and ends in chronic relapse. This persistent drug seeking despite adverse consequences and the will to stop using results, at least in part, from the conditioning that occurs during drug exposure. Environmental cues become associated with various aspects of the drug experience- such as the reward, the withdrawal, and the behavioral responses that are required to obtain the drug. Glutamate receptors are critically involved in each of these processes along the road to opiate addiction, despite the fact that opiate drugs exert their primary effects on the $\mu$ opioid receptor. These indirect effects on glutamate systems involve the prefrontal cortex, amygdala, and hippocampus,
\end{abstract}

all of which converge onto a nucleus accumbens output station that ultimately determines whether drug seeking occurs. Understanding the role of glutamate within the neural circuitry of opiate addiction is a critical first step toward novel therapeutics for relapse.

\section{THE MEMORY MOSAIC OF OPIATE ADDICTION}

Opiate addiction is a conglomerate of memories about the opiate experience, and when memory retrieval is triggered by the appropriate cues, relapse may occur. Different aspects of the drug experience, such as opiate reward and withdrawal, as well as the behavioral responses that led to the attainment of opiates, over time

Editors: R. Christopher Pierce and Paul J. Kenny

Additional Perspectives on Addiction available at www.perspectivesinmedicine.org

Copyright (C) 2012 Cold Spring Harbor Laboratory Press; all rights reserved; doi: 10.1101/cshperspect.a012088

Cite this article as Cold Spring Harb Perspect Med 2012;2:a012088 
become associated with various environmental cues that are repeatedly paired with them through a process termed "conditioning." During attempts to abstain from the drug, the addict may be confronted with a reminder cue that triggers retrieval of one or more of these conditioned memories. In the absence of appropriate inhibitory control, such events may drive relapse. Below we review what is known about the neurobiological underpinnings of these distinct conditioned memories, primarily drawing from rodent models of addiction.

\section{CONDITIONED REWARD AND AVERSION}

The rewarding effects of drugs of abuse can be studied using the conditioned place preference model (CPP). In this model, the animal learns to associate an environmental context with opiate reward. Treatments that affect the acquisition of CPP are likely involved in primary reward, whereas those that affect only the expression of CPP may be selectively involved in conditioned reward. Ventral tegmental area (VTA) $\mu$ opioid receptors mediate the primary rewarding effects of opiates (Wise 1989), and glutamatergic tone is required for the activating effects of opiates on dopamine neurons (Jalabert et al. 2011) (see Mazei-Robison and Nestler 2012; Ting-A-Kee and van der Kooy 2012). However, more and more evidence indicates that glutamate receptors are also critical for opiate reward. Below we review what is known about the types of glutamate receptors involved in opiate reward, based on evidence from CPP models.

The NMDA receptor (NMDA-R) stands out as the glutamate receptor subtype most commonly implicated in the rewarding effects of opiates. NMDA-R antagonists block both the acquisition and expression of morphine CPP (Tzschentke and Schmidt 1995; Tzschentke and Schmidt 1997; Popik et al. 1998, 2003a,b; Suzuki et al. 2000; Papp et al. 2002; Ribeiro Do Couto et al. 2004; Yonghui et al. 2006; Rezayof et al. 2007; Zarrindast et al. 2007; Heinmiller et al. 2009; Kao et al. 2011; Ma et al. 2011b). These effects are at least partly mediated by NR2B-containing NMDA-Rs, as NR2B-selective antagonists, such as ifenprodil, are capable of producing comparable effects (Suzuki et al. 1999; Narita et al. 2000; Ma et al. 2006, 2011b). Furthermore, an effective dose of ifenprodil does not alter spatial learning and memory in a nonopiate paradigm (Ma et al. 2011b), suggesting that these effects may be independent of context memory encoding. Collectively, these results suggest that NMDA, specifically NR2Bcontaining, receptor antagonists may devalue the primary reward of opiates.

The AMPA receptor (AMPA-R) and the metabotropic glutamate receptor 5 (mGluR5) have similarly been implicated in opiate conditioned reward. AMPA-R (Layer et al. 1993; Tzschentke and Schmidt 1997; Harris et al. 2004; ShabatSimon et al. 2008) and mGluR5 (Popik and Wrobel 2002; Aoki et al. 2004; Herzig and Schmidt 2004; Veeneman et al. 2011) antagonists block both the acquisition and expression of morphine CPP, and at least for the mGluR5 antagonist MPEP, effective doses do not alter spatial learning and memory in other tasks (Popik and Wrobel 2002). This pattern of results is strikingly similar to those observed with NMDA$\mathrm{R}$ antagonists. However, unlike NMDA-R antagonists (Tzschentke and Schmidt 1997; Papp et al. 2002), the effects of mGluR5 antagonists on acquisition can be explained by state dependence (Herzig and Schmidt 2004). Others have even observed a potentiation in morphine CPP with mGluR5 antagonists (van der Kam et al. 2009a,b; Rutten et al. 2011), suggesting that mGluR5 antagonists may partly substitute for opiate reward (Rutten et al. 2011).

Acute withdrawal from opiate drugs can produce an aversive state that is capable of inducing conditioned place aversion (CPA) in a manner comparable to the CPP that is induced by opiate reward. Experimentally, this acute withdrawal state is often elicited by injection of naloxone, a $\mu$ opioid receptor antagonist, in morphine-dependent animals. Interestingly, NMDA-R antagonists are capable of blocking both the acquisition and expression of naloxone-induced conditioned aversion (Blokhina et al. 2000; Maldonado et al. 2003; Kawasaki et al 2011). At least one study has documented similar effects on the acquisition of this CPA with an AMPA-R antagonist and broad-spectrum 
mGluR antagonists (Kawasaki et al. 2005). Furthermore, these effects were localized to the nucleus accumbens (Fig. 1a,b) (Kawasaki et al. 2011). These studies suggest that similar glutamatergic mechanisms underlie both morphine CPP and naloxone CPA.

Glutamate transporters also play an important role in opiate conditioned memories, by altering the level of glutamate available for binding its receptors. For example, inhibition of glutamate uptake with transporter blockers enhances acquisition of morphine CPP and naloxone CPA (Sekiya et al. 2004), whereas promoting glutamate uptake blocks the acquisition of morphine CPP (Fujio et al. 2005; Nakagawa et al. 2005a). These studies suggest that even indirect glutamate receptor agonists may enhance, whereas antagonists may prevent, opiate conditioned memories.

\section{CONDITIONED REINFORCEMENT}

By comparison to what is known about the role of glutamate in opiate conditioned reward, far less is known about its role in conditioned reinforcement. Conditioned reinforcement refers to the progressive ability of various opiate conditioned stimuli to drive behavioral responding for opiates. This is typically assessed using a self-administration paradigm, which, unlike the CPP paradigm, permits animals to control their own intake of the opiate drug by performing an operant response (such as nose poking or lever pressing). Indeed, contingent versus noncontingent forms of opiate administration have been shown to elicit different patterns of gene expression changes (Jacobs et al. 2005). The selfadministration paradigm is thus considered the gold standard for assessing addiction behavior because it takes into account several cognitive aspects, such as expectation, decision-making, and reward valuation, in the neurobiological response to opiates.

In general, however, effects on conditioned reinforcement in the self-administration paradigm support the observations on conditioned reward. For example, NMDA-R and AMPA-R antagonists increase rates of heroin self-administration and produce behavioral effects con- sistent with a decrease in opiate reward (Semenova et al. 1999; Xi and Stein 2002). Similar to its substitution-like effects in the CPP model, MPEP pretreatment reduces rates of heroin selfadministration (van der Kam et al. 2007), and rats will self-administer this mGluR5 antagonist intravenously (van der Kam et al. 2009b). Collectively, these observations suggest that effects on the acquisition of CPP or the self-administration of opiates, or in general, experimental phases in which the opiate drug is "on board," can be most parsimoniously explained by effects on primary reward. As such, effects on conditioned responses might best be studied under extinction conditions (see below).

\section{EXTINCTION AND REINSTATEMENT}

Extinction is a multifaceted term that is used to describe what is typically the second phase of the addiction model, in which opiate availability is removed, and the animal learns to stop responding for the drug and/or to stop expressing CPP. The term "extinction" is also used to refer to the inhibitory memory that is formed during this phase of the model. Certain cues associated with opiate reward can be extinguished, and the alternative, nonextinguished cues can be used to trigger reinstatement, or relapse. Often, the reinstatement test is also conducted under extinction conditions (e.g., opiate is unavailable). In addition to nonextinguished cues, reinstatement can be triggered by stress or noncontingent priming injections of the opiate drug. Stress circuits and primary reward mechanisms, respectively, contribute to these latter, very different forms of relapse (Bossert et al. 2005b).

Because NMDA-R and AMPA-R antagonists also block the expression of CPP (Layer et al. 1993; Tzschentke and Schmidt 1997; Popik et al. 1998; Papp et al. 2002; Popik et al. 2003a; Harris et al. 2004; Yonghui et al. 2006), their role clearly extends beyond primary reward. NR2B-containing NMDA-R antagonists are capable of reducing the expression of morphine $\mathrm{CPP}$ when they are administered during opiate abstinence (without explicit extinction training) (Ma et al. 2011b). They are also capable of preventing reinstatement of morphine CPP 
J. Peters and T.J. De Vries

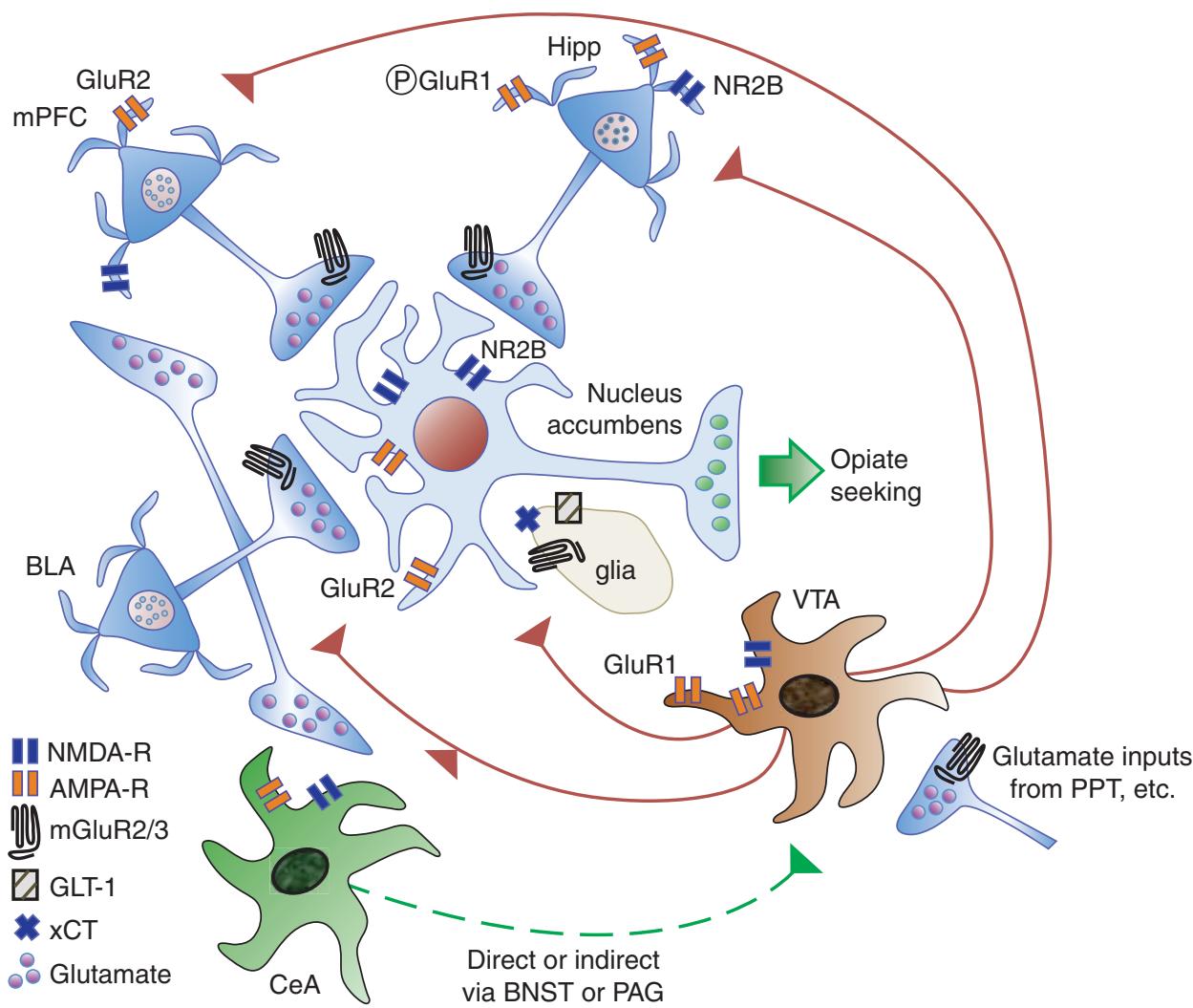

Individual elements referenced in the main text

a. AMPA-Rs in NAc on reward (Layer et al. 1993; Li et al. 2011b for GluR2-containing AMPA-Rs), on seeking (LaLumiere and Kalivas 2008), on aversion (Kawasaki et al. 2011)

b. NMDA-Rs in NAc on reward (Popik and Kolasiewicz 1999; Ma et al. 2007; Kao et al. 2011 for NR2B-containing NMDA-Rs), on aversion (Kawasaki et al. 2011), on NR2B-containing NMDA-Rs on seeking (Shen et al. 2011)

c. mGluR2/3 in NAc on seeking (Bossert et al. 2006)

d. $\mathrm{xCT}$ in NAc on seeking (Zhou and Kalivas 2008)

e. GluR2-containing AMPA-Rs in mPFC on seeking (Van den Oever et al. 2008)

f. GLT-1 in NAc on reward (Fujio et al. 2005)

g. NMDA-R in mPFC on reward (Bishop et al. 2011)

h. NMDA-R in CeA on reward (Rezayof et al. 2007; Li et al. 2008; Li et al. 2011a), on aversion (Watanabe et al. 2002; Glass et al. 2008)

i. AMPA-R in CeA on aversion (Watanabe et al. 2002)

j. NMDA-R in Hipp on reward (Zarrindast et al. 2007; Ma et al. 2007 for NR2B-containing NMDA-Rs), on aversion (Hou et al. 2009)

k. AMPA-R in Hipp on aversion (Hou et al. 2009), on extinction (Billa et al. 2009 for phospho-GluR1)

I. NMDA-R in VTA on reward (Popik and Kolasiewicz 1999; Harris et al. 2004), on reinforcement (Xi and Stein 2002)

m. AMPA-R in VTA on reward (Harris et al. 2004; Shabat-Simon et al. 2008; Carlezon et al. 1997 for GluR1-containing NMDA-Rs), on reinforcement $(\mathrm{X}$ and Stein 2002)

n. mGluR2/3 in VTA on seeking (Bossert et al. 2004)

Note: Although mGluR5s have been shown to produce effects on opiate reward and reinforcement when administered systemically, their loci of action in the brain have not been identified, and are therefore not depicted here.

Figure 1. Glutamate systems controlling opiate addiction. Three major glutamatergic inputs to the nucleus accumbens (NAc) arise from the medial prefrontal cortex (mPFC), hippocampus (Hipp), and basolateral amygdala (BLA) and regulate opiate reward and relapse. The BLA also projects to the mPFC and central nucleus of the amygdala (CeA) (see text for details). The CeA can access the ventral tegmental area (VTA) directly or through a relay in the bed nucleus of the stria terminalis (BNST) or periaqueductal gray (PAG). The VTA projects to all components of the circuit and modulates their activity. Output from NAc neurons drives relapse to opiate seeking. 
when administered in the days before the relapse test, under either extinction or abstinence conditions (Popik et al. 2006; Ma et al. 2011b). These results are consistent with the notion that NMDA-Rs are important for the persistent representation of opiate reward memory. When administered just before the reinstatement test, ifenprodil is effective at preventing morphineprimed, but not stress-induced, reinstatement of CPP (Ma et al. 2007), suggesting that NR2Bcontaining NMDA-Rs may not be necessary for all forms of reinstatement. AMPA-R antagonists applied locally to the nucleus accumbens are also capable of preventing reinstatement elicited by both discrete cues and heroin priming in a self-administration model (Fig. 1a) (LaLumiere and Kalivas 2008).

D-cycloserine, a partial NMDA-R agonist acting at the glycine-binding site, has been used to facilitate extinction memory formation (Davis et al.2006). Although this drug is effective at facilitating extinction of morphine CPA (Myers and Carlezon 2010), there is some evidence that it may not be effective at facilitating extinction of morphine CPP (Lu et al. 2011). Neither are NMDA-R antagonists effective at preventing extinction of morphine CPP (Popik et al. 1998) because, as mentioned above, they are involved in the persistent representation of opiate reward. Interestingly, in humans, the NMDA-R antagonist memantine effectively reduces heroin reward, but unfortunately, does not alter its reinforcement (Comer and Sullivan 2007). This is shown by the observation that subjective reports of liking and craving can be reduced, but when given the opportunity to self-administer heroin or receive money, addicts will still choose to selfadminister the drug (Comer and Sullivan 2007). This finding highlights the importance of distinguishing between reward and reinforcement, and the mechanisms regulating drug taking versus drug seeking, as treatments that prevent relapse should logically target the latter.

Disrupted glutamate homeostasis, particularly within the nucleus accumbens, has been proposed to underlie cocaine addiction (Kalivas 2009). For this psychostimulant, ambient levels of accumbens glutamate are dramatically reduced during withdrawal owing to decreased levels of the cysteine-glutamate exchanger (xCT) on glia (Baker et al. 2003). This is thought to result in reduced tone on presynaptic group II glutamate receptors (metabotropic glutamate receptor $2 / 3$ [mGluR2/3]) that regulate glutamate release (Moran et al. 2005). The possibility remains that mGluR2/3 receptors located predominantly on glia may participate in these effects as well. Regardless, restoring tone on these receptors with the mGluR2/3 agonist prevents relapse for both cocaine and heroin (Bossert et al. 2004, 2005a; Peters and Kalivas 2006), presumably by protecting against excessive release of glutamate from afferents to the accumbens (Fig. 1c) (Bossert et al. 2006; Peters and Kalivas 2006). In line with this, a recent study showed the ability of the cognitive enhancing drug, modafinil, to prevent heroin-primed reinstatement of heroin CPP, and this effect was mediated by mGluR2/3 receptors (Tahsili-Fahadan et al. 2010).

The aforementioned effects of mGluR2/3 agents in heroin reinstatement suggest that a similar pathology in accumbens glutamate may underlie both cocaine and heroin addiction. Consistent with this, $\mathrm{N}$-acetylcysteine, an overthe-counter drug that enhances cysteine-glutamate exchange through $\mathrm{xCT}$, has been shown to reduce heroin seeking in a self-administration model during both extinction and reinstatement (Fig. 1d) (Zhou and Kalivas 2008). Strikingly, this glutamate prodrug was capable of preventing multiple forms of reinstatement (e.g., both discrete cue- and heroin-induced) for up to 40 days after discontinuing treatment (Zhou and Kalivas 2008). In human cocaine addicts, $N$-acetylcysteine has been shown to effectively diminish the impact of cocaine-associated cues on cocaine craving (LaRowe et al. 2007), suggesting that the therapeutic potential of this drug may translate to human addicts.

\section{A SYSTEMS PERSPECTIVE ON OPIATE ADDICTION}

Thus far we have highlighted studies that examined the glutamatergic mechanisms of opiate addiction with systemic pharmacological manipulations. But where are these agents exerting 
their effects in the brain? We have already mentioned the nucleus accumbens, which is a critical output controlling opiate seeking. We discuss here the three major glutamatergic inputs to the accumbens that comprise the neural circuitry of opiate addiction. These include the medial prefrontal cortex ( $\mathrm{mPFC})$, the basolateral amygdala (BLA), and the hippocampus (Fig. 1). The VTA is also discussed, owing to its importance in modulating activity in these glutamatergic afferents to the accumbens. All of these brain regions, except the hippocampus, have been shown to be necessary for the reinstatement of heroin seeking in self-administration models of addiction (Bossert et al. 2004, 2006, 2011; Rogers et al. 2008). The hippocampus, however, is critical for opiate reward (Corrigall and Linseman 1988; Luo et al. 2004) and provides an important modulatory input to accumbens neurons (O’Donnell et al. 1999). We highlight below how interactions between these regions govern opiate addictive behaviors.

\section{PREFRONTAL-ACCUMBENS PATHWAYS}

The glutamatergic mPFC projection to the nucleus accumbens can be subdivided into a dorsal pathway from the prelimbic cortex (PL) subregion to the core, and a ventral pathway from the infralimbic cortex (IL) subregion to the shell (Sesack et al. 1989). Relapse for heroin relies on the dorsal projection from PL to core, as shown by an elegant study combining local inactivation of PL with microdialysis for glutamate in the accumbens core during a reinstatement session (LaLumiere and Kalivas 2008). These investigators observed a peak in glutamate within the core during reinstatement, but when PL was pharmacologically inactivated just before the reinstatement test, reinstatement was blocked, along with the corresponding rise in accumbens glutamate. NMDA-R and AMPA-R antagonists applied locally to the core were also sufficient to block reinstatement of heroin seeking (LaLumiere and Kalivas 2008; Shen et al. 2011). In fact, heroin relapse relies on LTP-like changes within the PL to core pathway mediated by an increase in cell membrane expression of NR2Bcontaining NMDA-Rs (Fig. 1b) (Shen et al.
2011). The importance of this PL projection to accumbens core has been shown not just for reinstatement of heroin seeking (LaLumiere and Kalivas 2008; Rogers et al. 2008), but also for cocaine seeking (McFarland et al. 2003, 2004), and for multiple types of reinstatement including cue-induced (LaLumiere and Kalivas 2008; Rogers et al. 2008), priming-induced (McFarland et al. 2003; LaLumiere and Kalivas 2008; Rogers et al. 2008), and stress-induced reinstatement (McFarland et al. 2004). As such, this projection has been proposed to be a "final common pathway" to relapse.

In addition to this dorsal projection from PL to core, reinstatement for heroin may also rely on the ventral system, as inactivation of IL (Rogers et al. 2008) or selective disruption of IL neuronal ensembles (Bossert et al. 2011) prevents reinstatement of heroin seeking induced by both discrete and contextual cues (Rogers et al. 2008; Bossert et al. 2011), as well as priming doses of heroin (Rogers et al. 2008). Preliminary evidence suggests that at least for context-induced reinstatement, the IL projection to the accumbens shell mediates this effect (Bossert et al. 2012). This might also be the case for heroin-induced reinstatement, as shell inactivation also prevents this form of relapse (Rogers et al. 2008). In contrast, for cocaine, the IL projection to the accumbens shell mediates the inhibition of drug seeking after extinction (Peters et al. 2008). This apparent divergence between the $\mathrm{mPFC}$ subregions controlling heroin versus cocaine addiction is particularly interesting in light of the observation that lesions of IL but not PL prevent the conditioned rewarding effects of morphine, whereas lesions of PL but not IL prevent those of cocaine (Tzschentke and Schmidt 1999).

A few studies have suggested that IL may also serve an inhibitory function in heroin subjects. For example, the inhibition of PKM $\zeta$ locally within IL prevents extinction memory retrieval for both morphine CPP and naloxone CPA (He et al. 2011), suggesting that the extinction memory may be stored in IL. In a selfadministration model, inhibiting the endocytosis of GluR2-containing AMPA-Rs locally within IL, but not PL, effectively prevented cue- 
induced reinstatement of heroin seeking and rescued IL neurons from a state of acute synaptic depression (Fig. 1e) (Van den Oever et al. 2008). Although the output of IL neurons was not directly assessed in this study, the pattern of results suggests an inhibitory function for IL on heroin seeking. Further research is necessary to resolve under which conditions IL facilitates versus inhibits heroin seeking.

\section{AMYGDALA OUTPUTS}

Although the BLA projection to the nucleus accumbens core is a likely candidate for controlling opiate-seeking behavior (LaLumiere and Kalivas 2008; Rogers et al. 2008), as it does for cocaine (Di Ciano and Everitt 2004), this has yet to be directly shown. However, inhibition of $\mathrm{PKM} \zeta$ locally within the BLA or the core prevents retrieval of the conditioned reward memory (He et al. 2011; Li et al. 2011b), and at least for the core, this effect requires endocytosis of GluR2-containing AMPA-Rs (Fig. 1a). The BLA-shell projection has also been implicated in morphine reward (Lintas et al. 2011). In this study, dopamine receptor antagonists in the BLAwere capable of altering neurophysiological responses of shell neurons to morphine (Lintas et al. 2011). The BLA potentiates shell neuronal activity in part via stimulation of NMDA-Rs (Floresco et al. 1998; Floresco et al. 2001). NMDA-R antagonists applied to the nucleus accumbens disrupt the acquisition, expression, and reinstatement of morphine CPP (Popik and Kolasiewicz 1999; Ma et al. 2007; Kao et al. 2011), at least in part through NR2B-containing NMDA-Rs (Fig. 1b) (Ma et al. 2007; Kao et al. 2011). Gene transfer of the glutamate transporter (glutamate transporter 1 [EAAT2] [GLT-1]) to the shell also blocks the acquisition of CPP (Fig. 1f) (Fujio et al. 2005). Thus the BLA-shell projection may be important for opiate conditioned reward. Notably, NMDA-R antagonists have no effect on conditioned heroin reinforcement when applied preferentially to the accumbens core (Pulvirenti et al. 1992).

The BLA projection to the MPFC may also be important for opiate conditioned reward (Fig. 1). NMDA-R antagonists applied locally within PL enhance CPP to subthreshhold doses of morphine (Fig. 1g), and this effect depends on activity within the BLA (Bishop et al. 2011). PL neurons increase their firing rate during expression of morphine CPP, consistent with the notion that activation of PL is a component of opiate conditioned reward (Sun et al. 2011). The BLA-mPFC projection also provides an indirect means by which the BLA can activate the nucleus accumbens. As the PL-core pathway has been proposed to be a "final common pathway" for reinstatement, activation of this pathway by BLA inputs is one putative route to relapse.

The central nucleus of the amygdala (CeA) also plays an important role in opiate addiction, and the BLA projects both directly and indirectly to this nucleus (Fig. 1) (Royer et al. 1999). NMDA-R and AMPA-R antagonists produce their effects on the acquisition of both CPP and CPA within the central nucleus of the amygdala (CeA) (Fig. 1h,i) (Watanabe et al. 2002; Rezayof et al. 2007; Glass et al. 2008). NMDA-Rs within the CeA are also capable of controlling the expression of CPP, and the downstream activation of ERK is required for this effect (Rezayof et al. 2007; Li et al. 2008, 2011a). The CeA is an output station to midbrain targets implicated in the aversive state that accompanies opiate withdrawal, including the VTA (Zahm et al. 2011) and periaqueductal gray (PAG) (Rizvi et al. 1991) (Fig. 1). The PAG has been noted for its role in pain associated with acute opiate withdrawal (Emmers 1985; Jacquet 1988).

The bed nucleus of the stria terminalis (BNST) is one possible intermediary between the CeA and its midbrain targets (Fig. 1) (Zahm et al. 2011). Evidence suggests that activity within the CeA and BNST during protracted withdrawal may produce a "stress-like" state that can precipitate relapse (Nakagawa et al. 2005b; Harris and Aston-Jones 2007). Indeed, for cocaine, these regions are only critical for reinstatement triggered by stress (McFarland et al. 2004). However, for heroin, they appear to be critical for both heroin-primed and discrete cue-induced reinstatement (Rogers et al. 2008), in addition to stress-induced reinstatement of opiate seeking (Shalev et al. 2001; Ma et al. 2008). Further, increases in fos expression in the BNST 
correlate with the degree of morphine CPP expression (Harris and Aston-Jones 2003), and lesions of the CeA disrupt naloxone-induced fos expression in the BNST (Nakagawa et al. 2005b). Collectively, these data suggest that activation of a CeA-BNST pathway may be a critical component of opiate seeking, and that a withdrawalinduced stress-like state may underlie this effect.

\section{THE HIPPOCAMPUS}

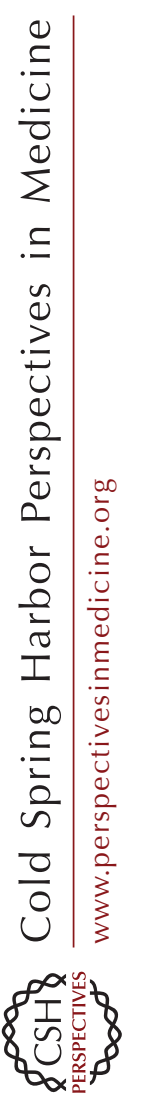

The hippocampus has extensive projections throughout the neural circuitry discussed thus far (van Strien et al. 2009), and is important for regulating the up and down states of nucleus accumbens neurons (O'Donnell et al. 1999), thereby gating the responsiveness to other inputs, such as those from the mPFC and the BLA. NMDA-R antagonists applied locally to the hippocampus are capable of blocking the acquisition, but not the expression, of both CPP and CPA (Fig. 1j) (Zarrindast et al. 2007; Hou et al. 2009). Hippocampal AMPA-Rs also mediate context-dependent opiate memories, as AMPA-R antagonists block the acquisition of CPA (Hou et al. 2009), and phosphorylation of the AMPA-R GluR1 subunit is required for context-dependent sensitization memory (Xia et al. 2011) and up-regulated by extinction of CPP (Fig. 1k) (Billa et al. 2009).

Although the role of the hippocampus in the primary rewarding effects of opiates has been conclusively established (Corrigall and Linseman 1988; Sell et al. 2000), evidence for the involvement of this structure in opiate seeking is lacking by comparison. However, reductions in spine density within the hippocampus occur only with self-administered, not experimenter-administered morphine (Robinson et al. 2002), suggesting that neuroadaptations within this structure occur with opiate seeking. Further, chronic opiate exposure can reduce adult neurogenesis in the hippocampus (Eisch et al. 2000), and altered functional connectivity of the hippocampus has been shown in human heroin addicts (Ma et al. 2011a). Therefore, future studies should be devoted to ascertaining the precise role of this region in opiate seeking using self-administration models of addiction.

\section{ASCENDING DOPAMINE PATHWAYS}

The VTA distributes dopamine projections throughout the cortex and striatum (Morgane et al. 2005) and is critically important in regulating opiate addictive behaviors (Wise 1989; Vargas-Perez et al. 2009; Lintas et al. 2011). NMDARs and AMPA-Rs located in the VTA are necessary for both the acquisition and expression of CPP (Fig. 1l,m) (Popik and Kolasiewicz 1999; Harris et al. 2004; Shabat-Simon et al. 2008). Whereas rostrally located AMPA-Rs control reward, the caudal ones control aversion (Carlezon et al. 2000; Shabat-Simon et al. 2008), effects mediated by GluR1-containing AMPA-Rs and subsequent cyclic AMP response element-binding protein (CREB) activation (Carlezon et al. 1997; Olson et al. 2005; Moron et al. 2010). Furthermore, the effects of NMDA-R and AMPA-R antagonists on conditioned reinforcement are also at least partially localized to the VTA (Xi and Stein 2002). The VTA is another site of action (Bossert et al. 2004), in addition to the nucleus accumbens mentioned above (Bossert et al. 2006), whereby mGluR2/3 agonists reduce reinstatement of opiate seeking (Fig. 1n). As in the accumbens, this might occur by reducing excessive glutamate release from afferent inputs, and the pedunculopontine tegmental (PPT) area is one likely candidate (Vargas-Perez et al. 2007; Ting-A-Kee and van der Kooy 2012).

Because the VTA is the major source of dopamine in the $\mathrm{mPFC}$, amygdala, and hippocampus (Fig. 1) (Morgane et al. 2005), we can infer an involvement of the VTA projection in cases in which local pharmacological manipulations of dopamine receptors produce effects on behavior. Lesions of the VTA projection to $\mathrm{mPFC}$ alter the conditioned rewarding effects of opiates (Narita et al. 2010), and dopamine D1 receptor blockade in PL prevents cue-induced reinstatement of heroin seeking (See 2009). This suggests that dopamine release in the VTA-PL pathway may initiate activation of the PL-accumbens core pathway and precipitate subsequent relapse, as it does for cocaine (McFarland and Kalivas 2001). It should be noted, however, that the role of accumbens dopamine depends on the form of reinstatement (Fig. 1), with shell 
dopamine controlling context-induced and core dopamine cue-induced reinstatement of heroin seeking (Bossert et al. 2007).

In the BLA, dopamine receptors regulate the acquisition of morphine CPP; however, the particular subtype of receptor mediating this effect depends critically on the opiate history of the animal (Lintas et al. 2011). That is, in opiatedependent rats, blockade of D2 receptors prevents morphine CPP acquisition, whereas in opiate-naïve rats, this effect is mediated by D1 receptors (Lintas et al. 2011). This underscores the importance of the VTA projection to BLA during the progression from opiate use to abuse. Indeed, chronic opiate administration leads to a switch in dopamine effects on BLA pyramidal neurons from inhibition to excitation, an effect that is mediated by presynaptic $\mathrm{D} 1$ receptors $(\mathrm{Li}$ et al. 2011c). Both D1 and D2 receptors are important for the acquisition and expression of morphine CPP in both the CeA (Rezayof et al. 2002; Zarrindast et al. 2003) and the hippocampus (Rezayof et al. 2003). In contrast, evidence for dopamine acting within the amygdala and hippocampus to effect opiate seeking in a selfadministration model is lacking.

\section{CONCLUSION}

In this review, we have attempted to highlight the importance of the multitude of memories that contribute to opiate addiction. Conditioned reward, aversion, and reinforcement processes recruit similar glutamatergic circuits to accomplish behaviors like approach and drug taking. The circuits controlling drug seeking under extinction conditions are of critical importance because these circuits are operative during states that precipitate relapse. By comparison to treatments that work on opiate primary reward, treatments that work on conditioned responses are lacking. The retrieval of conditioned memories, in the absence of sufficient inhibition by extinction memories, may trigger these conditioned responses and lead to relapse.

NMDA-Rs play a special role in opiate addiction in that they persistently maintain the representation of opiate primary reward (e.g., opiate value). Hence, NMDA-R antagonists have been examined for their efficacy, with some success in treating opiate addiction (Herman et al. 1995; Krupitsky et al. 2002; Comer and Sullivan 2007). MPEP and related mGluR5 antagonists have been proposed as an alternate therapy, which may be analogous to methadone treatment in that these compounds appear to partially substitute for the primary rewarding effects of opiates (van der Kam et al. 2009b; Rutten et al. 2011). AMPA-Rs and glial glutamate transporters have also proven important in animal models of addiction, but many of the compounds targeting these substrates have not yet been approved for use in humans. $\mathrm{N}$-acetylcysteine, a drug that corrects a reduction in glutamate availability from glia, offers an over-thecounter solution to a primary pathology in accumbens basal glutamate, and mGluR2/3 agonists are emerging as another means of correcting that same pathology.

Opiate circuits may be distinct from those for psychostimulants (Badiani et al. 2011) in that they engage both dorsal and ventral prefrontal-accumbens pathways for opiate seeking, and show a greater contribution from stress circuits during relapse. The latter is not surprising given that abstinence from opiates elicits a withdrawal syndrome characterized by acute elevations in cortisol (Nava et al. 2006) and a heightened cortisol response to opiate cues that predicts relapse propensity (Fatseas et al. 2011). The hippocampus has probably been underestimated for its contribution to opiate seeking, as its anatomical connectivity with other circuit components, and its role in opiate primary reward, is striking. An understanding of these neural circuits and the role of glutamate within each component should aid the development of intelligent therapeutics for opiate addiction.

\section{REFERENCES \\ * Reference is also in this collection.}

Aoki T, Narita M, Shibasaki M, Suzuki T. 2004. Metabotropic glutamate receptor 5 localized in the limbic forebrain is critical for the development of morphine-induced rewarding effect in mice. Eur J Neurosci 20: 1633-1638.

Badiani A, Belin D, Epstein D, Calu D, Shaham Y. 2011. Opiate versus psychostimulant addiction: The differences do matter. Nat Rev Neurosci 12: 685-700. 
J. Peters and T.J. De Vries

Baker DA, McFarland K, Lake RW, Shen H, Tang XC, Toda S, Kalivas PW. 2003. Neuroadaptations in cystine-glutamate exchange underlie cocaine relapse. Nat Neurosci 6: 743-749.

Billa SK, Sinha N, Rudrabhatla SR, Moron JA. 2009. Extinction of morphine-dependent conditioned behavior is associated with increased phosphorylation of the GluR1 subunit of AMPA receptors at hippocampal synapses. Eur J Neurosci 29: 55-64.

Bishop SF, Lauzon NM, Bechard M, Gholizadeh S, Laviolette SR. 2011. NMDA receptor hypofunction in the prelimbic cortex increases sensitivity to the rewarding properties of opiates via dopaminergic and amygdalar substrates. Cereb Cortex 21: 68-80.

Blokhina EA, Sukhotina IA, Bespalov AY. 2000. Pretreatment with morphine potentiates naloxone-conditioned place aversion in mice: Effects of NMDA receptor antagonists. Eur J Pharmacol 406: 227-232.

Bossert JM, Liu SY, Lu L, Shaham Y. 2004. A role of ventral tegmental area glutamate in contextual cue-induced relapse to heroin seeking. J Neurosci 24: 10726-10730.

Bossert JM, Busch RF, Gray SM. 2005a. The novel mGluR2/ 3 agonist LY379268 attenuates cue-induced reinstatement of heroin seeking. Neuroreport 16: 1013-1016.

Bossert JM, Ghitza UE, Lu L, Epstein DH, Shaham Y. 2005b. Neurobiology of relapse to heroin and cocaine seeking: An update and clinical implications. Eur J Pharmacol 526: $36-50$

Bossert JM, Gray SM, Lu L, Shaham Y. 2006. Activation of group II metabotropic glutamate receptors in the nucleus accumbens shell attenuates context-induced relapse to heroin seeking. Neuropsychopharmacology 31: 21972209.

Bossert JM, Poles GC, Wihbey KA, Koya E, Shaham Y. 2007. Differential effects of blockade of dopamine D1-family receptors in nucleus accumbens core or shell on reinstatement of heroin seeking induced by contextual and discrete cues. J Neurosci 27: 12655-12663.

Bossert JM, Stern AL, Theberge FR, Cifani C, Koya E, Hope BT, Shaham Y. 2011. Ventral medial prefrontal cortex neuronal ensembles mediate context-induced relapse to heroin. Nat Neurosci 14: 420-422.

Bossert JM, Stern AL, Theberge FR, Marchant NJ, Wang HL, Morales M, Shaham Y. 2012. Role of projections from ventral medial prefrontal cortex to nucleus accumbens shell in context-induced reinstatement of heroin seeking. J Neurosci 32: 4982-4991.

Carlezon WA Jr, Boundy VA, Haile CN, Lane SB, Kalb RG, Neve RL, Nestler EJ. 1997. Sensitization to morphine induced by viral-mediated gene transfer. Science 277: 812-814.

Carlezon WA Jr, Haile CN, Coppersmith R, Hayashi Y, Malinow R, Neve RL, Nestler EJ. 2000. Distinct sites of opiate reward and aversion within the midbrain identified using a herpes simplex virus vector expressing GluR1. J Neurosci 20: RC62.

Comer SD, Sullivan MA. 2007. Memantine produces modest reductions in heroin-induced subjective responses in human research volunteers. Psychopharmacology (Berl) 193: $235-245$.
Corrigall WA, Linseman MA. 1988. Conditioned place preference produced by intra-hippocampal morphine. Pharmacol Biochem Behav 30: 787-789.

Davis M, Ressler K, Rothbaum BO, Richardson R. 2006. Effects of D-cycloserine on extinction: Translation from preclinical to clinical work. Biol Psychiatry 60: 369-375.

Di Ciano P, Everitt BJ. 2004. Direct interactions between the basolateral amygdala and nucleus accumbens core underlie cocaine-seeking behavior by rats. J Neurosci 24: 7167-7173.

Eisch AJ, Barrot M, Schad CA, Self DW, Nestler EJ. 2000. Opiates inhibit neurogenesis in the adult rat hippocampus. Proc Natl Acad Sci 97: 7579-7584.

Emmers R. 1985. Stimulation of the periaqueductal gray subdues sensitized pain in morphine- and meperidinedependent rats. Exp Neurol 88: 405-417.

Fatseas M, Denis C, Massida Z, Verger M, Franques-Reneric P, Auriacombe M. 2011. Cue-induced reactivity, cortisol response and substance use outcome in treated heroin dependent individuals. Biol Psychiatry 70: 720-727.

Floresco SB, Yang CR, Phillips AG, Blaha CD. 1998. Basolateral amygdala stimulation evokes glutamate receptordependent dopamine efflux in the nucleus accumbens of the anaesthetized rat. Eur J Neurosci 10: 1241-1251.

Floresco SB, Blaha CD, Yang CR, Phillips AG. 2001. Dopamine D1 and NMDA receptors mediate potentiation of basolateral amygdala-evoked firing of nucleus accumbens neurons. J Neurosci 21: 6370-6376.

Fujio M, Nakagawa T, Sekiya Y, Ozawa T, Suzuki Y, Minami M, Satoh M, Kaneko S. 2005. Gene transfer of GLT-1, a glutamate transporter, into the nucleus accumbens shell attenuates methamphetamine- and morphine-induced conditioned place preference in rats. Eur J Neurosci 22: 2744-2754.

Glass MJ, Hegarty DM, Oselkin M, Quimson L, South SM, Xu Q, Pickel VM, Inturrisi CE. 2008. Conditional deletion of the NMDA-NR1 receptor subunit gene in the central nucleus of the amygdala inhibits naloxone-induced conditioned place aversion in morphine-dependent mice. Exp Neurol 213: 57-70.

Harris GC, Aston-Jones G. 2003. Enhanced morphine preference following prolonged abstinence: Association with increased Fos expression in the extended amygdala. $\mathrm{Neu}$ ropsychopharmacology 28: 292-299.

Harris GC, Aston-Jones G. 2007. Activation in extended amygdala corresponds to altered hedonic processing during protracted morphine withdrawal. Behav Brain Res 176: $251-258$

Harris GC, Wimmer M, Byrne R, Aston-Jones G. 2004. Glutamate-associated plasticity in the ventral tegmental area is necessary for conditioning environmental stimuli with morphine. Neuroscience 129: 841-847.

He YY, Xue YX, Wang JS, Fang Q, Liu JF, Xue LF, Lu L. 2011. PKM $\zeta$ maintains drug reward and aversion memory in the basolateral amygdala and extinction memory in the infralimbic cortex. Neuropsychopharmacology 36: 1972 1981.

Heinmiller A, Ting AKR, Vargas-Perez H, Yeh A, van der Kooy D. 2009. Tegmental pedunculopontine glutamate and GABA-B synapses mediate morphine reward. Behav Neurosci 123: 145-155. 
Herman BH, Vocci F, Bridge P. 1995. The effects of NMDA receptor antagonists and nitric oxide synthase inhibitors on opioid tolerance and withdrawal. Medication development issues for opiate addiction. Neuropsychopharmacology 13: 269-293.

Herzig V, Schmidt WJ. 2004. Effects of MPEP on locomotion, sensitization and conditioned reward induced by cocaine or morphine. Neuropharmacology 47: 973-984.

Hou YY, Liu Y, Kang S, Yu C, Chi ZQ, Liu JG. 2009. Glutamate receptors in the dorsal hippocampus mediate the acquisition, but not the expression, of conditioned place aversion induced by acute morphine withdrawal in rats Acta Pharmacol Sin 30: 1385-1391.

Jacobs EH, Smit AB, de Vries TJ, Schoffelmeer AN. 2005. Long-term gene expression in the nucleus accumbens following heroin administration is subregion-specific and depends on the nature of drug administration. Addict Biol 10: 91-100.

Jacquet YF. 1988. The NMDA receptor: Central role in pain inhibition in rat periaqueductal gray. Eur J Pharmacol 154: $271-276$

Jalabert M, Bourdy R, Courtin J, Veinante P, Manzoni OJ, Barrot M, Georges F. 2011. Neuronal circuits underlying acute morphine action on dopamine neurons. Proc Natl Acad Sci 108: 16446-16450.

Kalivas PW. 2009. The glutamate homeostasis hypothesis of addiction. Nat Rev Neurosci 10: 561-572.

Kao JH, Huang EY, Tao PL. 2011. NR2B subunit of NMDA receptor at nucleus accumbens is involved in morphine rewarding effect by siRNA study. Drug Alcohol Depend 118: $366-374$

Kawasaki Y, Jin C, Suemaru K, Kawasaki H, Shibata K, Choshi T, Hibino S, Gomita Y, Araki H. 2005. Effect of glutamate receptor antagonists on place aversion induced by naloxone in single-dose morphine-treated rats. $\mathrm{Br} \mathrm{J}$ Pharmacol 145: 751-757.

Kawasaki Y, Ishida S, Jin C, Kitamura Y, Kawasaki H, Gomita Y, Sendo T, Araki H. 2011. Effect of glutamate receptor antagonists microinjected into the nucleus accumbens on place aversion induced by naloxone in single-dose, morphine-treated rats. Eur J Pharmacol 666: 131-134.

Krupitsky E, Burakov A, Romanova T, Dunaevsky I, Strassman R, Grinenko A. 2002. Ketamine psychotherapy for heroin addiction: Immediate effects and two-year followup. J Subst Abuse Treat 23: 273-283.

LaLumiere RT, Kalivas PW. 2008. Glutamate release in the nucleus accumbens core is necessary for heroin seeking. J Neurosci 28: 3170-3177.

LaRowe SD, Myrick H, Hedden S, Mardikian P, Saladin M, McRae A, Brady K, Kalivas PW, Malcolm R. 2007. Is cocaine desire reduced by $\mathrm{N}$-acetylcysteine? Am J Psychiatry 164: 1115-1117.

Layer RT, Uretsky NJ, Wallace LJ. 1993. Effects of the AMPA/ kainate receptor antagonist DNQX in the nucleus accumbens on drug-induced conditioned place preference. Brain Res 617: 267-273.

Li YQ, Li FQ, Wang XY, Wu P, Zhao M, Xu CM, Shaham Y, Lu L. 2008. Central amygdala extracellular signal-regulated kinase signaling pathway is critical to incubation of opiate craving. J Neurosci 28: 13248-13257.
Li F, Wang XS, Dai RP, Zhang JY, Zhou XF, Hao W, Li CQ. 2011a. The activation of NMDA receptor-ERK pathway in the central amygdala is required for the expression of morphine-conditioned place preference in the rat. $\mathrm{Neu}$ rotox Res 20: 362-371.

Li YQ, Xue YX, He YY, Li FQ, Xue LF, Xu CM, Sacktor TC, Shaham Y, Lu L. 2011b. Inhibition of PKM $\zeta$ in nucleus accumbens core abolishes long-term drug reward memory. J Neurosci 31: 5436-5446.

Li Z, Luan W, Chen Y, Chen M, Dong Y, Lai B, Ma L, Zheng P. 2011c. Chronic morphine treatment switches the effect of dopamine on excitatory synaptic transmission from inhibition to excitation in pyramidal cells of the basolateral amygdala. J Neurosci 31: 17527-17536.

Lintas A, Chi N, Lauzon NM, Bishop SF, Gholizadeh S, Sun N, Tan H, Laviolette SR. 2011. Identification of a dopamine receptor-mediated opiate reward memory switch in the basolateral amygdala-nucleus accumbens circuit J Neurosci 31: 11172-11183.

Lu GY, Wu N, Zhang ZL, Ai J, Li J. 2011. Effects of d-cycloserine on extinction and reinstatement of morphine-induced conditioned place preference. Neurosci Lett 503: 196-199.

Luo F, Xi ZX, Wu G, Liu C, Gardner EL, Li SJ. 2004. Attenuation of brain response to heroin correlates with the reinstatement of heroin-seeking in rats by fMRI. Neuroimage 22: 1328-1335.

Ma YY, Guo CY, Yu P, Lee DY, Han JS, Cui CL. 2006. The role of NR2B containing NMDA receptor in place preference conditioned with morphine and natural reinforcers in rats. Exp Neurol 200: 343-355.

Ma YY, Chu NN, Guo CY, Han JS, Cui CL. 2007. NR2Bcontaining NMDA receptor is required for morphinebut not stress-induced reinstatement. Exp Neurol 203: 309-319.

Ma DY, Xu MY, Yang HC, Yang LZ. 2008. Effect of inhibition of the central nucleus of the amygdala and drug experience on the regions underlying footshock-induced reinstatement of morphine seeking. J Int Med Res 36: $992-1000$.

Ma N, Liu Y, Fu XM, Li N, Wang CX, Zhang H, Qian RB, Xu HS, Hu X, Zhang DR. 2011a. Abnormal brain defaultmode network functional connectivity in drug addicts. PLOS ONE 6: e16560.

Ma YY, Yu P, Guo CY, Cui CL. 2011b. Effects of ifenprodil on morphine-induced conditioned place preference and spatial learning and memory in rats. Neurochem Res 36: 383-391.

Maldonado C, Cauli O, Rodriguez-Arias M, Aguilar MA, Minarro J. 2003. Memantine presents different effects from MK-801 in motivational and physical signs of morphine withdrawal. Behav Brain Res 144: 25-35.

* Mazei-Robison MS, Nestler EJ. 2012. Opiate-induced molecular and cellular plasticity of ventral tegmental area and locus coeruleus catecholamine neurons. Cold Spring Harb Perspect Med doi: 10.1101/cshperspect.a012070.

McFarland K, Kalivas PW. 2001. The circuitry mediating cocaine-induced reinstatement of drug-seeking behavior. J Neurosci 21: 8655-8663.

McFarland K, Lapish CC, Kalivas PW. 2003. Prefrontal glutamate release into the core of the nucleus accumbens 
J. Peters and T.J. De Vries

mediates cocaine-induced reinstatement of drug-seeking behavior. J Neurosci 23: 3531-3537.

McFarland K, Davidge SB, Lapish CC, Kalivas PW. 2004. Limbic and motor circuitry underlying footshock-induced reinstatement of cocaine-seeking behavior. $\mathrm{J} \mathrm{Neu}$ rosci 24: $1551-1560$.

Moran MM, McFarland K, Melendez RI, Kalivas PW, Seamans JK. 2005. Cystine/glutamate exchange regulates metabotropic glutamate receptor presynaptic inhibition of excitatory transmission and vulnerability to cocaine seeking. J Neurosci 25: 6389-6393.

Morgane PJ, Galler JR, Mokler DJ. 2005. A review of systems and networks of the limbic forebrain/limbic midbrain. Prog Neurobiol 75: 143-160.

Moron JA, Gullapalli S, Taylor C, Gupta A, Gomes I, Devi LA. 2010. Modulation of opiate-related signaling molecules in morphine-dependent conditioned behavior: Conditioned place preference to morphine induces CREB phosphorylation. Neuropsychopharmacology 35: 955-966.

Myers KM, Carlezon WA Jr. 2010. D-cycloserine facilitates extinction of naloxone-induced conditioned place aversion in morphine-dependent rats. Biol Psychiatry 67: 85-87.

Nakagawa T, Fujio M, Ozawa T, Minami M, Satoh M. 2005a. Effect of MS-153, a glutamate transporter activator, on the conditioned rewarding effects of morphine, methamphetamine and cocaine in mice. Behav Brain Res 156: 233-239.

Nakagawa T, Yamamoto R, Fujio M, Suzuki Y, Minami M, Satoh M, Kaneko S. 2005b. Involvement of the bed nucleus of the stria terminalis activated by the central nucleus of the amygdala in the negative affective component of morphine withdrawal in rats. Neuroscience 134: 9-19.

Narita M, Aoki T, Suzuki T. 2000. Molecular evidence for the involvement of NR2B subunit containing $N$-methyl-Daspartate receptors in the development of morphine-induced place preference. Neuroscience 101: 601-606.

Narita M, Matsushima Y, Niikura K, Takagi S, Nakahara K, Kurahashi K, Abe M, Saeki M, Asato M, Imai S, et al. 2010. Implication of dopaminergic projection from the ventral tegmental area to the anterior cingulate cortex in $\mu$-opioid-induced place preference. Addict Biol 15: 434447.

Nava F, Caldiroli E, Premi S, Lucchini A. 2006. Relationship between plasma cortisol levels, withdrawal symptoms and craving in abstinent and treated heroin addicts. $J$ Addict Dis 25: 9-16.

O’Donnell P, Greene J, Pabello N, Lewis BL, Grace AA. 1999. Modulation of cell firing in the nucleus accumbens. Ann NY Acad Sci 877: 157-175.

Olson VG, Zabetian CP, Bolanos CA, Edwards S, Barrot M, Eisch AJ, Hughes T, Self DW, Neve RL, Nestler EJ. 2005. Regulation of drug reward by cAMP response elementbinding protein: Evidence for two functionally distinct subregions of the ventral tegmental area. J Neurosci 25: 5553-5562.

Papp M, Gruca P, Willner P. 2002. Selective blockade of drug-induced place preference conditioning by ACPC, a functional NDMA-receptor antagonist. Neuropsychopharmacology 27: 727-743.
Peters J, Kalivas PW. 2006. The group II metabotropic glutamate receptor agonist, LY379268, inhibits both cocaine- and food-seeking behavior in rats. Psychopharmacology (Berl) 186: 143-149.

Peters J, LaLumiere RT, Kalivas PW. 2008. Infralimbic prefrontal cortex is responsible for inhibiting cocaine seeking in extinguished rats. J Neurosci 28: 6046-6053.

Popik P, Kolasiewicz W. 1999. Mesolimbic NMDA receptors are implicated in the expression of conditioned morphine reward. Naunyn Schmiedebergs Arch Pharmacol 359: $288-294$.

Popik P, Wrobel M. 2002. Morphine conditioned reward is inhibited by MPEP, the mGluR5 antagonist. Neuropharmacology 43: 1210-1217.

Popik P, Mamczarz J, Fraczek M, Widla M, Hesselink M, Danysz W. 1998. Inhibition of reinforcing effects of morphine and naloxone-precipitated opioid withdrawal by novel glycine site and uncompetitive NMDA receptor antagonists. Neuropharmacology 37: 1033-1042.

Popik P, Kozela E, Wrobel M, Wozniak KM, Slusher BS. 2003a. Morphine tolerance and reward but not expression of morphine dependence are inhibited by the selective glutamate carboxypeptidase II (GCP II, NAALADase) inhibitor, 2-PMPA. Neuropsychopharmacology 28: 457-467.

Popik P, Wrobel M, Rygula R, Bisaga A, Bespalov AY. 2003b. Effects of memantine, an NMDA receptor antagonist, on place preference conditioned with drug and nondrug reinforcers in mice. Behav Pharmacol 14: 237-244.

Popik P, Wrobel M, Bisaga A. 2006. Reinstatement of morphine-conditioned reward is blocked by memantine. Neuropsychopharmacology 31: 160-170.

Pulvirenti L, Maldonado-Lopez R, Koob GF. 1992. NMDA receptors in the nucleus accumbens modulate intravenous cocaine but not heroin self-administration in the rat. Brain Res 594: 327-330.

Rezayof A, Zarrindast MR, Sahraei H, Haeri-Rohani AH. 2002. Involvement of dopamine D2 receptors of the central amygdala on the acquisition and expression of morphine-induced place preference in rat. Pharmacol Biochem Behav 74: 187-197.

Rezayof A, Zarrindast MR, Sahraei H, Haeri-Rohani A. 2003. Involvement of dopamine receptors of the dorsal hippocampus on the acquisition and expression of morphine-induced place preference in rats. J Psychopharmacol 17: 415-423.

Rezayof A, Golhasani-Keshtan F, Haeri-Rohani A, Zarrindast MR. 2007. Morphine-induced place preference: Involvement of the central amygdala NMDA receptors. Brain Res 1133: 34-41.

Ribeiro Do Couto B, Aguilar MA, Manzanedo C, Rodriguez-Arias M, Minarro J. 2004. Effects of NMDA receptor antagonists (MK-801 and memantine) on the acquisition of morphine-induced conditioned place preference in mice. Prog Neuropsychopharmacol Biol Psychiatry 28: 1035-1043.

Rizvi TA, Ennis M, Behbehani MM, Shipley MT. 1991. Connections between the central nucleus of the amygdala and the midbrain periaqueductal gray: Topography and reciprocity. J Comp Neurol 303: 121-131.

Robinson TE, Gorny G, Savage VR, Kolb B. 2002. Widespread but regionally specific effects of experimenter- 
versus self-administered morphine on dendritic spines in the nucleus accumbens, hippocampus, and neocortex of adult rats. Synapse 46: 271-279.

Rogers JL, Ghee S, See RE. 2008. The neural circuitry underlying reinstatement of heroin-seeking behavior in an animal model of relapse. Neuroscience 151: 579-588.

Royer S, Martina M, Pare D. 1999. An inhibitory interface gates impulse traffic between the input and output stations of the amygdala. J Neurosci 19: 10575-10583.

Rutten K, Van Der Kam EL, De Vry J, Bruckmann W, Tzschentke TM. 2011. The mGluR5 antagonist 2-methyl-6-( phenylethynyl)-pyridine (MPEP) potentiates conditioned place preference induced by various addictive and non-addictive drugs in rats. Addict Biol 16: 108-115.

See RE. 2009. Dopamine D1 receptor antagonism in the prelimbic cortex blocks the reinstatement of heroin-seeking in an animal model of relapse. Int J Neuropsychopharmacol 12: 431-436.

Sekiya Y, Nakagawa T, Ozawa T, Minami M, Satoh M. 2004 Facilitation of morphine withdrawal symptoms and morphine-induced conditioned place preference by a glutamate transporter inhibitor DL-threo- $\beta$-benzyloxyaspartate in rats. Eur J Pharmacol 485: 201-210.

Sell LA, Morris JS, Bearn J, Frackowiak RS, Friston KJ, Dolan RJ. 2000. Neural responses associated with cue evoked emotional states and heroin in opiate addicts. Drug Alcohol Depend 60: 207-216.

Semenova S, Danysz W, Bespalov A. 1999. Low-affinity NMDA receptor channel blockers inhibit acquisition of intravenous morphine self-administration in naive mice. Eur J Pharmacol 378: 1-8.

Sesack SR, Deutch AY, Roth RH, Bunney BS. 1989. Topographical organization of the efferent projections of the medial prefrontal cortex in the rat: An anterograde tracttracing study with Phaseolus vulgaris leucoagglutinin. J Comp Neurol 290: 213-242.

Shabat-Simon M, Levy D, Amir A, Rehavi M, Zangen A. 2008. Dissociation between rewarding and psychomotor effects of opiates: Differential roles for glutamate receptors within anterior and posterior portions of the ventral tegmental area. J Neurosci 28: 8406-8416.

Shalev U, Morales M, Hope B, Yap J, Shaham Y. 2001. Timedependent changes in extinction behavior and stress-induced reinstatement of drug seeking following withdrawal from heroin in rats. Psychopharmacology (Berl) 156: 98-107.

Shen H, Moussawi K, Zhou W, Toda S, Kalivas PW. 2011. Heroin relapse requires long-term potentiation-like plasticity mediated by NMDA2b-containing receptors. Proc Natl Acad Sci 108: 19407-19412.

Sun N, Chi N, Lauzon N, Bishop S, Tan H, Laviolette SR. 2011. Acquisition, extinction, and recall of opiate reward memory are signaled by dynamic neuronal activity patterns in the prefrontal cortex. Cereb Cortex 21: 26652680.

Suzuki T, Kato H, Tsuda M, Suzuki H, Misawa M. 1999. Effects of the non-competitive NMDA receptor antagonist ifenprodil on the morphine-induced place preference in mice. Life Sci 64: PL151-PL156.

Suzuki T, Kato H, Aoki T, Tsuda M, Narita M, Misawa M. 2000. Effects of the non-competitive NMDA receptor antagonist ketamine on morphine-induced place preference in mice. Life Sci 67: 383-389.

Tahsili-Fahadan P, Carr GV, Harris GC, Aston-Jones G. 2010. Modafinil blocks reinstatement of extinguished opiate-seeking in rats: Mediation by a glutamate mechanism. Neuropsychopharmacology 35: 2203-2210.

* Ting-A-Kee R, van der Kooy D. 2012. The neurobiology of opiate motiviation. Cold Spring Harb Perspect Med doi: 10.1101/cshperspect.a012096.

Tzschentke TM, Schmidt WJ. 1995. N-methyl-D-aspartic acid-receptor antagonists block morphine-induced conditioned place preference in rats. Neurosci Lett 193: $37-40$.

Tzschentke TM, Schmidt WJ. 1997. Interactions of MK-801 and GYKI 52466 with morphine and amphetamine in place preference conditioning and behavioural sensitization. Behav Brain Res 84: 99-107.

Tzschentke TM, Schmidt WJ. 1999. Functional heterogeneity of the rat medial prefrontal cortex: Effects of discrete subarea-specific lesions on drug-induced conditioned place preference and behavioural sensitization. Eur J Neurosci 11: 4099-4109.

van den Oever MC, Goriounova NA, Li KW, Van der Schors RC, Binnekade R, Schoffelmeer AN, Mansvelder HD, Smit AB, Spijker S, De Vries TJ. 2008. Prefrontal cortex AMPA receptor plasticity is crucial for cue-induced relapse to heroin-seeking. Nat Neurosci 11: 1053-1058.

van der Kam EL, de Vry J, Tzschentke TM. 2007. Effect of 2methyl-6-(phenylethynyl) pyridine on intravenous selfadministration of ketamine and heroin in the rat. Behav Pharmacol 18: 717-724.

van der Kam EL, De Vry J, Tzschentke TM. 2009a. 2-Methyl6-(phenylethynyl)-pyridine (MPEP) potentiates ketamine and heroin reward as assessed by acquisition, extinction, and reinstatement of conditioned place preference in the rat. Eur J Pharmacol 606: 94-101.

van der Kam EL, De Vry J, Tzschentke TM. 2009b. The mGlu5 receptor antagonist 2-methyl-6-( phenylethynyl)pyridine (MPEP) supports intravenous self-administration and induces conditioned place preference in the rat. Eur J Pharmacol 607: 114-120.

Van Strien NM, Cappaert NL, Witter MP. 2009. The anatomy of memory: An interactive overview of the parahippocampal-hippocampal network. Nat Rev Neurosci 10: $272-282$.

Vargas-Perez H, Ting-A-Kee RA, Heinmiller A, Sturgess JE, van der Kooy D. 2007. A test of the opponent-process theory of motivation using lesions that selectively block morphine reward. Eur J Neurosci 25: 3713-3718.

Vargas-Perez H, Ting-A-Kee RA, Walton CH, Hansen DM, Razavi R, Clarke L, Bufalino MR, Allison DW, Steffensen SC, van der Kooy D. 2009. Ventral tegmental area BDNF induces an opiate-dependent-like reward state in naive rats. Science 324: 1732-1734.

Veeneman MM, Boleij H, Broekhoven MH, Snoeren EM, Guitart Masip M, Cousijn J, Spooren W, Vanderschuren LJ. 2011. Dissociable roles of mGlu5 and dopamine receptors in the rewarding and sensitizing properties of morphine and cocaine. Psychopharmacology (Berl) 214: 863-876.

Watanabe T, Nakagawa T, Yamamoto R, Maeda A, Minami M, Satoh M. 2002. Involvement of glutamate receptors 
J. Peters and T.J. De Vries

within the central nucleus of the amygdala in naloxoneprecipitated morphine withdrawal-induced conditioned place aversion in rats. Jpn J Pharmacol 88: 399-406.

Wise RA. 1989. Opiate reward: Sites and substrates. Neurosci Biobehav Rev 13: 129-133.

Xi ZX, Stein EA. 2002. Blockade of ionotropic glutamatergic transmission in the ventral tegmental area reduces heroin reinforcement in rat. Psychopharmacology (Berl) 164: $144-150$.

Xia Y, Portugal GS, Fakira AK, Melyan Z, Neve R, Lee HT, Russo SJ, Liu J, Moron JA. 2011. Hippocampal GluA1-containing AMPA receptors mediate contextdependent sensitization to morphine. J Neurosci 31: 16279-16291.

Yonghui L, Xigeng Z, Yunjing B, Xiaoyan Y, Nan S. 2006. Opposite effects of MK-801 on the expression of food and morphine-induced conditioned place preference in rats. J Psychopharmacol 20: 40-46.
Zahm DS, Cheng AY, Lee TJ, Ghobadi CW, Schwartz ZM, Geisler S, Parsely KP, Gruber C, Veh RW. 2011. Inputs to the midbrain dopaminergic complex in the rat, with emphasis on extended amygdala-recipient sectors. J Comp Neurol 519: 3159-3188.

Zarrindast MR, Rezayof A, Sahraei H, Haeri-Rohani A, Rassouli Y. 2003. Involvement of dopamine D1 receptors of the central amygdala on the acquisition and expression of morphine-induced place preference in rat. Brain Res 965: 212-221.

Zarrindast MR, Lashgari R, Rezayof A, Motamedi F, NazariSerenjeh F. 2007. NMDA receptors of dorsal hippocampus are involved in the acquisition, but not in the expression of morphine-induced place preference. Eur J Pharmacol 568: 192-198.

Zhou W, Kalivas PW. 2008. N-acetylcysteine reduces extinction responding and induces enduring reductions in cueand heroin-induced drug-seeking. Biol Psychiatry 63: $338-340$. 


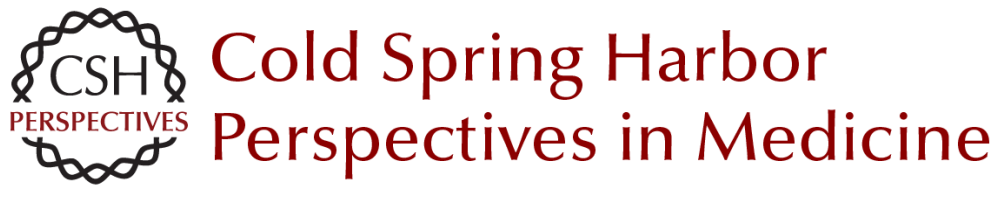

\section{Glutamate Mechanisms Underlying Opiate Memories}

Jamie Peters and Taco J. De Vries

Cold Spring Harb Perspect Med 2012; doi: 10.1101/cshperspect.a012088

Subject Collection Addiction

Developments from Bulk Optogenetics to Single-Cell Strategies to Dissect the Neural Circuits that Underlie Aberrant Motivational States Jose Rodriguez-Romaguera, Vijay M.K. Namboodiri, Marcus L. Basiri, et al.

Consequences of Parental Opioid Exposure on Neurophysiology, Behavior, and Health in the Next Generations

Fair M. Vassoler and Mathieu E. Wimmer

Animal Models of the Behavioral Symptoms of Substance Use Disorders Louk J.M.J. Vanderschuren and Serge H. Ahmed

Translational Research in Nicotine Addiction Miranda L. Fisher, James R. Pauly, Brett Froeliger, et al.

Neonatal Opioid Withdrawal Syndrome (NOWS): A Transgenerational Echo of the Opioid Crisis Andrew E. Weller, Richard C. Crist, Benjamin C. Reiner, et al.

Impairment of Synaptic Plasticity by Cannabis, $\Delta^{\mathbf{9}}$ -THC, and Synthetic Cannabinoids

Alexander F. Hoffman, Eun-Kyung Hwang and Carl R. Lupica

Drug-Evoked Synaptic Plasticity of Excitatory Transmission in the Ventral Tegmental Area Camilla Bellone, Michael Loureiro and Christian Lüscher

Opioid-Induced Molecular and Cellular Plasticity of Ventral Tegmental Area Dopamine Neurons Marie A. Doyle and Michelle S. Mazei-Robison
The Persistent Challenge of Developing Addiction Pharmacotherapies

Sarah E. Swinford-Jackson, Charles P. O'Brien, Paul J. Kenny, et al.

Opioid Modulation of the Gut-Brain Axis in Opioid-Associated Comorbidities

Li Zhang and Sabita Roy

Epigenetics of Drug Addiction Andrew F. Stewart, Sasha L. Fulton and lan Maze

Genetic Vulnerability to Opioid Addiction Brian Reed and Mary Jeanne Kreek

Glutamatergic Systems and Memory Mechanisms Underlying Opioid Addiction Jasper A. Heinsbroek, Taco J. De Vries and Jamie Peters

Mechanisms of Nicotine Addiction Marina R. Picciotto and Paul J. Kenny

Neural Substrates and Circuits of Drug Addiction Matthew W. Feltenstein, Ronald E. See and Rita A. Fuchs

The Role of the Central Amygdala in Alcohol Dependence Marisa Roberto, Dean Kirson and Sophia Khom

For additional articles in this collection, see http://perspectivesinmedicine.cshlp.org/cgi/collection/ 